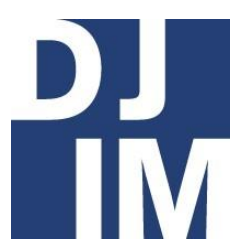

Volume 14

Spring

2018

djim.management.dal.ca |

\title{
Managing Copyright in Digital Collections: A Focus on Creative Commons Licences
}

Caroline Korbel

School of Information Management, Dalhousie University

\begin{abstract}
Digital collections in public institutions can benefit from Creative Commons licences, as they allow the responsible sharing and use of information online by faculty, students, researchers, and the public at large. This essay outlines major aspects of the proper management of Creative Commons licences in the following order: first, the current state of copyright in Canada; second, the way in which the Creative Commons functions and its relation to free culture and Open Access; third, Creative Commons for public institution collections, not just as a holding body, but as a repository; fourth, tools for managing Creative Commons licences online, including digital rights management (DRM) and technological protection measures (TPMs); and fifth, future impacts of the Creative Commons on digital collections. Creative Commons licences offer libraries the opportunity to expand their patronage and explore broader uses of their collections.
\end{abstract}

\section{Introduction}

To ensure legal compliance, public institutions and repositories, such as libraries, museums, post-secondary schools, and archives, must properly manage the copyright and licences of their digital collections to ensure legal compliance. Because they allow the responsible sharing and use of information online by faculty, students, researchers, and the public at large, Creative Commons licenses can offer significant benefits for public institutions with digital collections. Creative Commons licensing can motivate new users to access and use the expressions it protects, which encourages these new patrons to make use 
of materials in new and innovative ways. This essay outlines the proper management of Creative Commons in the following order: first, I will briefly outline the current state of copyright in Canada; second, I will discuss how the Creative Commons licences function and their relation to free culture and Open Access; third, I will discuss the Creative Commons for public institution collections, as a holding body and as a repository; fourth, having established the relationship between the Creative Commons and digital collections, I will recommend tools for managing Creative Commons licences online; and fifth, I will discuss the future impacts of the Creative Commons on digital collections.

\section{In Brief, Copyright in Canada}

Copyright in Canada is dictated by the Copyright Act and is one of the four areas of intellectual property, along with patents and trademarks, that is concerned with the protection of forms of expression. An expression needs to be in a tangible form, such as "literary, dramatic, musical, and artistic works; performers' performances; sound recordings; [and] broadcast signals" (Murray \& Trosow, 2013, p. 36). Copyright's importance lies in its definition of the rights of creators and the users of creations (Jordan, 2006), which are applicable and protected whether or not copyright is defended (Murray \& Trosow, 2013). A work can only be granted copyright if it is in a fixed form and that form is an original expression, as under Canadian copyright, facts and ideas are not copyrightable
(Murray \& Trosow, 2013). Under the Canadian Copyright Act there are areas of exception to copyright. There are two exceptions of particular relevance: an exception for libraries, archives and museums for the maintenance or management of their collections (s 30.1), and a fair dealing exception for "research, private study, education, parody or satire" (s 29). In order to use a Creative Commons licence, copyright must already be established.

\section{Creative Commons}

Creative Commons licences can be applied on top of copyright. They allow the legal owners of works to make their work available with limits as to how it is to be used by the public, and as such, the institute or person must have copyright ownership of the work to apply Creative Commons licences (Harris, 2014). Thus, all Creative Commons licences respect national copyright laws in their application. To adapt to the needs of creators and owners, the Creative Commons (2017c) created a three-layered approach to designing their licences:

1. Legal code: the traditional legal tool to determine the limits of the licence (para. 5)

2. Commons Deed ("human readable"): the plain-language version of the legal code, so that users are able understand the licence and use it appropriately (para. 6)

Managing Copyright in Digital Collections 
3. CC Rights Expression Language (CC REL) ("machine readable"): a format that "software systems, search engines, and other kinds of technology understand." (para. 7)

The combination of these three layers allows Creative Commons licences to be understood by law, people (both creators and users), and machines. As Harris notes in his book, Canadian Copyright Law, these "licences are not flexible, and a creator has to choose the one that most closely meets his or her needs" (2014, p. 212). To maintain balance between these three layers, the legal code has to be stable, and so four licencing conditions were created and set.

There are four licence conditions an owner can choose from, which can then be combined in six ways. The Creative Commons states the following four licence conditions (2017d):

- Attribution (mandatory requirement): the creator must be credited when a user makes use of their works, but the attribution cannot suggest that the creator endorses the new work (para. 5).

- ShareAlike (sa): the creator allows users to "copy, distribute, display, perform, and modify" (Creative Commons, 2017d, para. 5) the creation, but that new modified work must be published/released under the same Creative Commons licence (para. 5). Should the user want different conditions for their work, he/she requires the creator's permission (Creative Commons, 2017d, para. 5). Managing Copyright in Digital Collections
Creative Commons notes that their ShareAlike condition was "inspired by the GNU General Public License, used by many free and open source software projects" (2017d, para. 3).

- NonCommerical (nc): the creator allows users to "copy, distribute, display, perform,... (unless you have chosen NoDerivatives) modify, and use" (Creative Commons, 2017d, para. 6) the creation as the user chooses, but the use of the work cannot have a commercial purpose unless permitted by the creator (para. 6).

- NoDerivatives (nd): the creator allows users to "copy, distribute, display and perform only original copies" (Creative Commons, 2017d, para. 7) of the creation, but if users want to modify the creation in any way, they must have the creator's permission to do so (para. 7).

These four conditions are the basis for all Creative Commons licences and need to be fully understood by the creator or owner of copyright, so that they can dictate the most appropriate and beneficial use of their work(s) and the user of the work.

From these four conditions, there are six possible licence types:

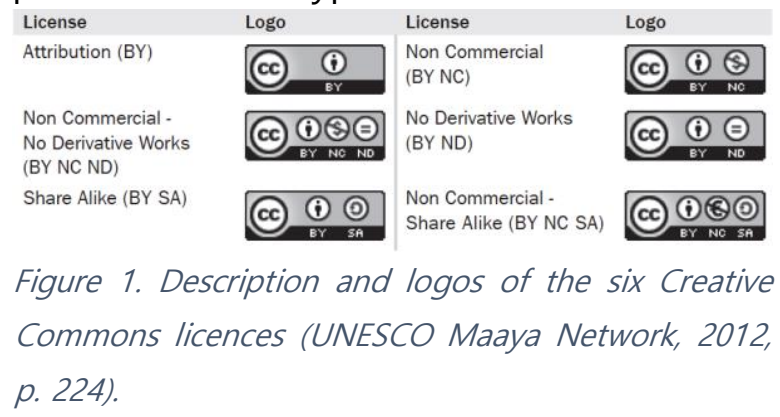

p. 224). 
"In essence, Creative Commons licences allow a creator to choose which rights from the copyright bundle to reserve, and which to waive" (Murray \& Trosow, 2013, p. 229). Each creator chooses the licence that best suits their work and their hopes for its future use, and after limits are established, every user is responsible for respecting those limits.

Any public institution or repository that holds public domain works can also benefit from a Public Domain Mark, also known as a "No Known Copyright" dedication (see Figure 2):

\section{PUBLIC}

DOMAIN

Figure 2. Icon of the Creative Commons Public Domain Mark (Creative Commons, 2017e).

This dedication notifies the user that the work has fallen in the public domain, either by circumstances of enough time passing or because the creator of the work has waived their rights (Creative Commons, 2017a). Works in the public domain are free for users to use in any way.

In recent years, there has been a movement towards openness and sharing, such as "'copyleft,' 'free culture,' 'Open Access,' 'Access to Knowledge $\left(\mathrm{A}_{2} \mathrm{~K}\right)$,' and many more (Murray \& Trosow, 2013, p. 228). Open Access, generally, is meant as the legal free distribution and use of research online (i.e., credible online publications that distribute free material online for the public). Often, Open Access policies use Creative Commons licences, as Open
Access is not an explicit licence (Jordan, 2006). Along with Creative Commons licences, there are many different licences (e.g., General Public License) that aim to balance attribution and originality with the encouragement of creative endeavors. Murray and Trosow (2013) observe that "[s]pecific licenses have become a way of marking a certain vision of the Internet, in which access to information goods, their transformation into something new, and their redistribution to another creator-inwaiting is experienced as an ongoing process" (p. 229-230). Cultures and movements that encourage openness and the sharing of works are using copyright and licences to encourage human creativity. Now, with the breadth and connectivity of the Internet, owners and users can responsibly share and build on works, and licences are a way of creating ". . . a public good without waiting for the law to tell them how, where, or when" (Murray \& Trosow, 2013, p. 230).

\section{Limitations}

Though Creative Commons licences give creators a say over their work's future use, there are drawbacks to these agreements, including the requirement of copyright, a loss of control, and a lack of future flexibility. As Mewhorn observes in his 2012 report, Creative Commons licenses: Options for Canadian open data providers, the main restriction of a Creative Commons licence is that its "... terms and restrictions ... only apply to works protected by copyright. Therefore, in Canada, the terms will not Managing Copyright in Digital Collections 
apply to pure 'facts', nor to works in which no author invests any non-trivial 'skill and judgment" (pp. 11-12). Copyright, and subsequently Creative Commons, requires that a form of expression be more than just an idea or facts; a "non-trivial" amount of the creator's "'skill and judgement" (Mewhorn, 2012, p. 12) that results in a fixed and original work. Mewhorn (2012) also notes that Creative Commons requires a creator to give up their control of the data (or other items) placed under the Creative Commons licence (p. 14). However, the Creative Commons licence gives a creator or licence holder finite control of how a work can and should be used (Mewhorn, 2012, p. 14). The last limitation of the Creative Commons licence is the lack of flexibility when choosing (and having chosen) a licence that suits the creator's needs. The licences are "best fit" options, but they ignore all other potential combinations of the four conditions. After deciding upon a suitable licence, the creator cannot change the limits on that work, which maintains a consistent relationship between creator, their work, and users over time. However, a licence does not account for "changing one's mind." No one can know all the potential uses of their work; thus, the Creative Commons can only address the uses currently in existence without limiting the uses that have yet been invented. All of these limitations should be considered carefully before entering a Creative Commons licence.

\section{Digital Collections}

The National Information Standards Organization (NISO) dictates in their fifth collections principle that "a good collection respects intellectual property rights" (2007, p. 13). The NISO's fifth collections principle outlines three considerations for digital collections' rights management:

- what rights the owners of the original source materials retain in their materials;

- what rights or permissions the collection developers have to digitize content and/or make it available; and

- what rights or permissions the users of the digital collection are given, to make subsequent use of the materials. (2007, p. 13)

The above considerations are a balancing of creator and user rights. The copyright owner must decide how to balance the protection of expression with the ways it can potentially be used (Scassa, 2005). It is the responsibility of a digital collection's curator to ensure that balance between the materials and their uses is maintained.

Digital collections have a lot to gain from Creative Commons licences, as they allow the use of the collection in ways that were previously restricted. With Creative Commons licences, public digital collections will inform users how materials should be used and allows copyright owners to control future use of materials. In addition, digital collection repositories 
can further state their own terms of use so that their users are aware of the repositories' preferences (Murray \& Trosow, 2013).

\section{Public Institutions and Repositories}

Under the current Copyright Act, educational institutions and repositories already receive exceptions for fair dealing and education. Also, as a library, archive, or museum, they reserve the right to manage and maintain collections, so copies are allowed in specific circumstance without infringing on copyright (Murray \& Trosow, 2013). Educational institutions and repositories are likely to own the copyright to the material (either in explicit agreements or through public domain), so adding a Creative Commons licence to some collections would be legal and reasonable. Furthermore, Creative Commons licences have been adopted by educational projects, such as the Public Library of Science (PLOS) and MIT's Open Courseware program (Murray \& Trosow, 2013). New areas of research, especially for educational institutions, can use Creative Commons licences for educational and sharing purposes. As Mewhort (2012) notes, "Creative Commons licenses can be adopted for - and remain compatible with - works from governments, educational institutions, private sector organizations, and individuals. The licenses can apply to all copyrighted data ..." (p. 10). Institutions should see Creative Commons as an opportunity for their digital collections to be used in a non-traditional manner, which has strong potential to increase users at that institution. In addition, Creative Commons offers global, not just national/local protection, to online, publicly-accessible digital collections (Mewhort, 2012, p. 11).

Jordan (2006) highlights two advantages to Creative Commons licences in digital collections that are especially beneficial for libraries. First, works under a Creative Commons licence can be freely distributed, ensuring that the work is legally shared at the institution (Jordan, 2006). Second, Creative Commons licences ensure that there is no ambiguity as to what the user is permitted (Jordan, 2006). These two advantages of Creative Commons save an institution or repository the need for separate and specific policies, as well as the potential time spent negotiating distribution rights (Jordan, 2006). Jordan also observed that though there are few digital collections that make use of Creative Commons licences, more collections are starting to make use of the licences and Creative Commons licencing tools have also appeared in platforms like DSpace (Jordan, 2006).

Data and software are new areas that are already seeing the benefits of Creative Commons, General Public, and Open Source licences. The World Intellectual Property Organization (WIPO) states that, "[s]uch projects, including the open source movement, which specializes in creating computer programs, also build their Managing Copyright in Digital Collections 
business models on the existence of copyright protection, because otherwise they could not set specific terms or create an obligation for subsequent users" (2016, p. 20). With proper Creative Commons controls, users can make use of data and software from public institutions and repositories to create new and innovative expressions. In addition, post-secondary institutions, especially research institutions with federal support, are moving towards publishing their research and sharing their data in an Open Access repository, often falling under the purview of either an archive or library. This support of Open Access can encourage the use of Creative Commons licences in academia, research institutions, and government, and even encourage the general public to make use of digital collections.

\section{Digital Rights Management Tools and Creative Commons}

Managers of digital collections need to be familiar with legal structures, current resources, and digital rights management models. Lipinski's 2013 book, The Librarian's Legal Companion for Licensing Information Resources and Services, is a thorough guide for anyone managing licences and dedicates a chapter to Creative Commons considerations. The Creative Commons also hosts a comprehensive website that outlines all the fine points and necessities of Creative Commons licences. A full and up-to-date list of the various considerations before entering into a Creative Commons licence Managing Copyright in Digital Collections is available for licensors and licensees (Creative Commons, 2017b). This is an excellent resource for creators, institutions, and users. In addition, it is important for a digital collection to have a set management model so that the Creative Commons licence can become a part of the workflow. If an institution is using the OAIS Reference Model, Creative Commons licences are a crucial part of descriptive information that will inform the data management of the collection (OAIS, 2000).

It is important to note that the management of rights will be required on the object level for digital collections. Creative Commons licences are applicable to individual works, not collections, so, as Sabharwal observes, "[d]ue to the heterogeneous nature of the collections, a boiler-place creative commons license will not be appropriate. Digitizing and publishing oral histories, for instance, will require permission from all copyright holders before the editing process" (2015, p. 103). Each collection and its objects are individual and unique and must be treated as such with their rights management plan.

For the proper rights management of digital objects and works, an institution or repository must have a thorough Digital Rights Management (DRM) plan. As Murray and Trosow (2013) state, "DRM is a mechanism by which owners or vendors of digital intellectual goods can control access to and use of the materials they make public or sell to consumers... [l]t can help creators or businesses publicize their work 
online without giving it away" (pp. 138143). There are tools that fall under DRM's purview that help manage rights and limit access to works according to those rights: technological protection measures (TPMs) and rights management information (RMI) (Murray \& Trosow, 2013). These measures, TPMs in particular, either limit copying capabilities or produce low-quality copies (or watermarked copies) so that copying is avoided or obvious (WIPO, 2016). There are many different types of DRMs and TPMs available depending on the medium and format of a work, but it is important to choose the system and technology that best suits the institution or repository's digital collection.

For works licensed under Creative Commons licences, the Creative Commons wrote its own code for works, licences, and metadata licences to be protected online. In 2008, the Creative Commons has developed the Creative Commons Rights Expression Language (ccREL), which is "the standard recommended by Creative Commons (CC) for machine-readable expression of copyright licensing terms and related information" (Creative Commons, 2008, para. 3). For best interoperability with other online mediums, the Creative Commons built ccREL based on the WorldWide Web Consortium's Resource Description Framework (RDF) (2008). In detail, the ccREL outlines the classes, permissions, requirements, prohibitions, licence properties, and work properties (Creative Commons, n.d.). The ccREL controls the use of work through metadata descriptions and website controls, ensuring that only appropriate and designated uses of a work are permitted, either through the work itself or the website's licence properties (Creative Commons, 2008). In addition, the collection's metadata itself is copyrightable and can have a Creative Commons licence. Creative Commons Zero Public Domain Dedication (CCO) is also known as "No Rights Reserved" or shown as the following:

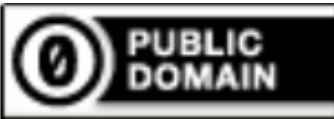

Figure 3. Creative Commons Zero Public Domain Dedication (CCO) icon (Creative Commons, 2017a).

This dedication indicates that the creator or owners of copyright or databases have waived their rights, and so anyone is able to use or aggregate their metadata (Creative Commons, 2017a). Aggregators and database builders can make use of these works to help collect or build new websites or databases. Public institutions and repositories can benefit from the increased diverted traffic from aggregators and can benefit from each other's good metadata or database creation.

Though DRM allows public institutions and repositories confidence that works are used according to their licence, there are limitations to such controls. The largest and most pronounced limitation is that a "DRM is technology set, and isolated from use, so no matter the intended use or legal limitations, DRM would not discriminate" Managing Copyright in Digital Collections 
(Murray \& Trosow, 2013, p. 142). This limitation is echoed in both Le Crosnier and WIPO, as a locked network or system cannot understand the context of a user's access to a work (UNESCO Maaya Network, 2012; WIPO, 2016). Another limitation is that DRM ". . . can also be used less benevolently to assert claims or regulate practices beyond the bounds of copyright" (Murray \& Trosow, 2013, pp. 140-141). Though DRM offers many protections, it is important to balance a user's potential needs and not abuse locked systems. If a user continually has problems accessing a work that he/she has a right to use, then the DRM, rights, and licence of that work is being violated. Managers of rights information need to be careful not to overextend their reach and infringe upon users' rights.

\section{Future Impact}

Creative Commons licences on digital collections can have implications for the future use and usability of those collections. As Murray and Trosow's (2013) last chapter shows, many questions need to be asked and answered on the topics of technology, post-secondary support, digital rights management, and legal reform. Technology is constantly developing, and rights have to be maintained during these major shifts in technological development, both for existing works and for technologies yet to be developed. For public institutions and repositories, being able to maintain and preserve digital collections without infringing on the rights Managing Copyright in Digital Collections of the works is paramount, and technology both encourages and deters these objectives. Post-secondary institutions' continued support of information sharing and openness of research and data is critical for propagating the values of the Creative Commons. Digital rights management needs to be carefully monitored for any changes that might infringe upon either the creators' or users' rights. Lastly, the basis of Creative Commons is copyright law, so any person maintaining copyright needs to keep abreast of developments in Canadian and International copyright law. Anyone who is tasked with the management of a digital collection and its works' rights should follow these areas with great interest.

\section{Conclusion}

Though the future of openness is uncertain, Creative Commons licences offer digital collections control over the use of their works. Through thoughtful consideration of the appropriate Creative Commons licences and DRM, a digital collection can be secure while balancing the creator's and user's rights and needs. Adding Creative Commons licences to certain works can encourage both current and future use of their digital collections. The potential benefits examined here highlight the need for further exploration of how Creative Commons licensing can encourage a new and better relationship between creators, users, and public institutions. 


\section{References}

Copyright Act, RSC, 1985, c C-42.

Creative Commons. (n.d.). Describing

copyright in RDF: Creative

Commons Rights Expression

Language. Retrieved from

https://creativecommons.org/ns

Creative Commons. (2008, May 1). ccREL:

The Creative Commons Rights

Expression Language. W3C.

Retrieved from

https://www.w3.org/Submission/ccR

EL/

Creative Commons. (2017a). CC0.

Retrieved from

https://creativecommons.org/shareyour-work/public-domain/cc0/

Creative Commons. (2017b, November 1).

Frequently asked questions.

Retrieved from

https://creativecommons.org/faq/\#

How_should_I_decide_which_license _to_choose.3F

Creative Commons. (2017c). Licensing considerations. Retrieved from: https://creativecommons.org/shareyour-work/licensing-considerations/

Creative Commons. (2017d). Licensing types. Retrieved from: https://creativecommons.org/share- your-work/licensing-types-

examples/

Creative Commons. (2017e). Public Domain Mark. Retrieved from https://creativecommons.org/shareyour-work/public-domain/pdm/

Gulley, N. (2013). Creative Commons: Challenges and solutions for researchers: A publisher's perspective of copyright in an open access environment. Insights: The UKSG Journal, 26(2), 168-173.

Retrieved from https://doaj.org/article/b1a838bbf6 b04855983b17b4f36430dd

Harris, L.E. (2014). Canadian copyright law ( $4^{\text {th }}$ ed.). Hoboken, NJ: John Wiley $\&$ Sons Inc.

Jordan, M. (2006). Chapter 3: Copyright and digital library collection. In Putting content online: A practical guide for libraries (37-51). Oxford, UK: Chandos Publishing.

Lavoie, B. (2000, January/February). Meeting the challenges of digital preservation: The OAIS reference model. OCLC Newsletter, 243, 2630. Retrieved from https://www.oclc.org/research/publi cations/library/2000/lavoieoais.html 
Lipinski, T. A. (2013). The librarian's legal companion for licensing information resources and services.

Chicago: American Library Association.

Mewhort, K. (2012, June 1). Creative Commons licenses: Options for Canadian open data providers. Ottawa, ON: Samuelson-Glushko Canadian Internet Policy and Public Interest Clinic, University of Ottawa. Retrieved from the Canadian Electronic Library.

Murray, L.J., \& Trosow, S.E. (2013). Canadian copyright: $A$ citizen's guide $\left(2^{\text {nd }}\right.$ ed.). Toronto, ON: Between the Lines.

National Information Standards Organization (NISO). (2007, December). A framework of guidance for building good digital collections ( $3^{\text {rd }}$ ed.). Baltimore, MD: National Information Standards Organization (NISO). Retrieved from http://www.niso.org/sites/default/fil es/2017-08/framework3.pdf

Sabharwal, A. (2015). Digital curation in the digital humanities: Preserving and promoting archival and special collections. Elsevier Science. Retrieved from ProQuest Ebook Central.
Scassa, T. (2005). Interest in the balance. Michael Geist (Ed.), In The public interest: The future of Canadian copyright law (pp. 41-65). Toronto, ON: Irwin Law. Retrieved from https://www.irwinlaw.com/sites/defa ult/files/attached/One_02_Scassa.pd $f$

UNESCO Maaya Network. (2012). Net.Lang: Towards the multilingual cyberspace. L. Vannini \& H. Le Crosnier (Eds.). Caen, France: C\&F éditions. Retrieved from http://www.unesco.org/fileadmin/M ULTIMEDIA/HQ/Cl/Cl/pdf/netlang_E N_pdfedition.pdf

World Intellectual Property Organization (WIPO). (2016). Understanding copyright and related rights. Geneva: World Intellectual Property Organization. Retrieved from http://www.wipo.int/edocs/pubdocs /en/wipo_pub_909_2016.pdf 